Reynolds, F. \& Vivat, B. (2006). Narratives of art-making in chronic fatigue syndrome/ myalgic encephalomyelitis: three case studies. Arts in Psychotherapy, $33,435-445$.

\begin{abstract}
This paper explores the narratives of three women who had lived with severe chronic fatigue syndrome/myalgic encephalomyelitis (CFS/ME) for many years, and who engaged in art-making as a leisure activity rather than for psychotherapy. Three distinct narratives about the role of art-making in CFS/ME were inferred. One participant represented art as a way of filling time rather than having further psychological significance. In her narrative, art provided satisfaction but also functioned as a witness to time and opportunity that had been lost to an unchanging illness. The second participant narrated both illness and art-making as intertwined journeys towards a more able and useful self. Her narrative had features of the quest described in previous typologies. The third participant also provided a quest narrative, but her struggle focused inwards on understanding her feelings about her illness and its effects on her life. The analytic focus on narrative revealed the distinctive constructions of illness and art-making that are usually submerged when qualitative analysis focuses on themes common to groups of participants. These narratives of artmaking in CFS/ME have relevance to understanding the multi-faceted therapeutic benefits of art.
\end{abstract}

Keywords: chronic fatigue, ME, art, narrative, qualitative 


\section{Narratives of art-making in chronic fatigue syndrome/ myalgic encephalomyelitis: three case studies}

Narratives help people to make sense of their life histories, and to integrate changes in self and identity, such as those brought about by chronic illness (Crossley, 2000; Polkinghorne, 1988). This paper examines the dominant narratives presented by three women who had lived with ME (myalgic encephalomyelitis) or CFS (chronic fatigue syndrome) for many years and who engaged in art-making as a leisure activity. Previous research has demonstrated that 'lay' arts practitioners (who are neither art therapists nor clients) are able to perceive symbolic or metaphorical meanings in at least some of their artwork, and that such meanings are experienced as relevant to the process of coping with chronic illness (Reynolds, 2002).

Narratives, or the stories that we tell about our lives, are inevitably shaped not only by real events, but by personal perceptions and the wider social context (including the relationship between narrator and audience). Whitehead (2006) describes narratives as having a plot or core story which impose order and reduce uncertainty about the illness experience. Crossley (2000, p. 21) argues that narratives convey choices that the teller has made about 'self, responsibility, blame and morality'.

Illness narratives have been categorised in various ways. Frank (1995) for example, identified three types. 'Restitution' narratives frame illness as a relatively predictable process of temporarily becoming ill and then returning to health. 'Chaos' narratives, in contrast, present a life with little meaning, order or progression. When describing illness, a chaos narrative reveals 'only an incessant present with no memorable past and no future worth anticipating' (Frank, 1995, p. 99). For Frank, 'quest' narratives - the third narrative type - are the most common type of story told 
about chronic illness. These narratives are popular for both narrators and listeners because they convey an optimistic message that the narrator has gained something positive from experiencing illness, such as revised priorities, or more authentic relationships. Whitehead (2006) applied this typology to the narratives of men and women living with $\mathrm{CFS} / \mathrm{ME}$, finding that restitution narratives were common in accounts of the early phases of illness, reflecting participants' confidence that they would recover from what they understood to be an acute viral condition. Chaos narratives tended to appear later, once individuals were plunged into uncertainty about their future and started to question whether they would ever recover from their chronic fatigue and other difficulties. Most of the participants also included a quest narrative when describing their later experiences of illness, in that they represented CFS/ME as bringing about positive changes in their priorities and perspectives.

Crossley (2000) offered a somewhat different classification of illness narratives, based on her interviews with people who were HIV-positive. She distinguished between conversion/growth, normalising, and loss narratives. All carry important implications for the person's sense of self, orientation towards the future, and subjective well-being. Conversion/growth narratives emphasise psychological and emotional growth, and revised priorities. There is an emphasis on living more fully in the present. Normalising narratives minimise the impact of illness on the self, and future plans. Loss narratives emphasise the limitations imposed by illness, and dwell 'on what could have been' (Crossley, 2000, p. 151). This paper examines whether the typologies suggested by Frank and Crossley are helpful for analysing the narratives that women with $\mathrm{CFS} / \mathrm{ME}$ offer about the role of art-making in their lives.

Myalgic encephalomyelitis (ME) is one of the terms used to describe a syndrome marked by severe chronic fatigue. Alternative terms are chronic fatigue syndrome (CFS) or CFIDS (Chronic Fatigue Immune Deficiency Syndrome), 
according to Munson (2000). CFS/ME is an illness (or constellation of illnesses) characterised by the presence of extreme fatigue. Participation in work and other everyday activities on a regular and reliable basis is difficult, if not impossible. In addition to fatigue, CFS/ME is associated with impaired memory and concentration, muscle or joint pain, sore throat, headache, and poor sleep (Fukuda, Straus, Hickie, Sharpe, Dobbins \& Komaroff, 1994), and a very poor quality of life (Anderson \& Ferrans, 1997). With CFS/ME, there is the additional burden of stigmatisation, as the illness is contested within both medical and wider social circles (Clarke \& James, 2003). Formal diagnosis is difficult to establish, and, perhaps because symptoms commonly fluctuate from day to day, sufferers encounter high levels of disbelief about their illness from family and friends, who may imply that the sufferer is exaggerating her symptoms, or is not trying hard enough to recover ( $\AA$ sbring \& Närvänen, 2002; Ware, 1998).

Little has been published on the meanings of art-making for people disabled by CFS/ME, although art therapy has been described as helpful for people coping with chronic pain, a common aspect of chronic fatigue conditions. In art therapy, clients are enabled to express feelings that they cannot put into words, helping them to grieve, move on and discover inner strengths. Camic (1999) discusses how art not only provides distraction away from chronic pain but brings the person fully into the present. Art can help a person to find meaning in their condition, experience agency, and live with pain.

A previous study of the meanings of art-making for women living with chronic illness included some participants who lived with CFS/ME (Reynolds, 2002). Participants ascribed many symbolic, hidden or oblique meanings to their artwork, even though this was created during leisure time rather than for formal therapy. Certain pieces were thought to represent the pain and suffering of illness. Others 
documented a journey from grief to hope; moved the participant out of the empty present; demonstrated mastery; expressed spiritual values; witnessed transcendence; and/or signified a newly emerged, stronger identity. However, there was little exploration of participants' unique perspectives or contexts. This paper seeks to address this limitation by focusing on three individual case studies.

Art-making is a multi-faceted activity and case studies of individuals in art therapy have shown that individuals living with serious illness each find different resources or meanings within their artwork, as shown by the content of their art as well as their narratives about it. For example, Borgmann (2002) presented three case studies of women living with cancer. One used art to explore her body disfigurement in symbolic terms. Another struggled to impose order on the chaos of grieving, finally choosing to depict in symbolic terms 'the things that made her strong' (p. 249). The third participant used her art to express her journey through cancer. She connected her past, present and future self in symbolic ways through, for example, drawing a bridge, map and landscape in which she placed herself.

Bullington, Sjöström-Flanagan, Nordemar \& Nordemar (2005) presented case studies of two women who engaged in expressive arts therapy to cope with fibromyalgia pain of uncertain origin. One engaged primarily in dance movement therapy and the other engaged in music therapy and drawing. The authors argued that nonverbal therapies are valuable for people living with chronic pain because they start more directly with the 'body and emotions' rather than with cognitive representations and verbalizations, helping the client to hear 'what the body has to say'. The richly detailed case studies showed the women, over a period of months, initially resisting new insights but gradually gaining a sense of new possibilities through their expressive work. They learned that they could impose some order and control over the chaos of the pain experience. 
As shown by Borgmann (2002) and by Bullington et al. (2005), case studies provide an opportunity to examine both the recurring and distinctive patterns in participants' narratives about art. Whilst simple generalisation from the findings is not possible, case studies can provide insights that contribute to theory-building and therapy practice (Yin, 1994).

This paper explores the meanings of art-making as a leisure activity for three women living with CFS/ME. Specifically, the study focused on the narratives, or core stories, that the participants told about in their art-making and artwork in the context of CFS/ME, exploring whether previous typologies can be applied. For the purpose of this study, 'art-making' is defined as any form of visual art or craft, including painting, textile art, hand-made cards and small gift items.

\section{Method}

Participants:

Three women with CFS/ME provide the focus for this study. They were White British women, aged 51, 60 and 62 years old. All had lived with CFS/ME for at least 16 years. Two had professional careers prior to developing chronic fatigue and one had mainly been a home-maker. The youngest participant mainly painted in watercolour, and the other participants mostly engaged in textile art. Participants were assured of anonymity, so pseudonyms are used for each case study.

\section{Procedure:}

The research project, including all materials sent to participants, was approved by the ethics committee at the host institution. Advertisements were placed in national (UK) arts magazines to invite people who were living with a chronic illness and who engaged in art-making to participate in interviews. Potential participants were 
provided with full information about the project, including the main interview questions, before giving consent. Participants were assured of confidentiality. In-depth qualitative interviews were carried out to explore participants' descriptions of the CFS/ME experience, their reflections on their reasons for artmaking, and their symbolic or metaphorical interpretations of specific pieces of artwork. The analysis looked for recurring themes and metaphors in order to identify participants' core narratives.

All interviews were carried out by the first author and lasted between 50 minutes to two hours. They were audio-recorded and fully transcribed. The interviews were wide-ranging and semi-structured, starting with a 'grand tour' question that invited narrative about self and illness (Could you tell me about yourself?). Further questions are indicated below. They were presented flexibly to guide free-flowing narrative:

2. Could you describe some of the ways in which your health and day-to-day life have been affected by your illness?

3. How did your interest in the visual arts begin? What influenced you?

4. What forms of artwork give you most satisfaction? Can you describe what is satisfying about creative activity?

5. Do you regularly use certain techniques, or a preferred style? Does your work express certain themes? Have these changed over time during your illness?

6. Do you think that your artwork has helped you to express your feelings about your illness - or not? What other themes do you express in your artwork?

7. Do you have any immediate or long-term future plans for creative projects?

8. Do you now consider yourself as an artist - is this an important aspect of your selfimage?

9. In what ways has your artistic work helped you to manage/ live with your health problems? 
Data analysis:

Like Bullington et al. (2005), and Whitehead (2006), the authors used no preset method of analysis. No assumptions were made at the outset regarding the types of narratives that might be present in the interview material. The analysis proceeded through a sequence of steps that is common in qualitative research, of immersion, detection of recurring themes or patterns in the interview data, search for core stories, and attention to metaphors. Analysis proceeded through a reiterative process, with the two researchers meeting to discuss emerging issues. The transcripts were analyzed with a view to noting both similarities and differences in the narratives of CFS/ME and art-making across the three participants.

\section{Findings}

\section{Case 1: Sharon - Artwork is 'just something to do with my hands'.}

Sharon emphasized her family roles in her opening self-description during the interview. But ME also seemed to be self-defining as it featured from the very start of her story: 'I'm sixty, I'm married with three grown sons, I've had ME for eighteen years'.

Like the other two participants, Sharon's story attributed the start of CFS/ME to an influenza illness. Unlike the other two participants, Sharon did not describe strong support within the family. Her husband was only mentioned in negative terms, for example as being away from home a great deal and as having recovered from influenza when she did not. Sharon described the initial onset of her illness: 'My husband ... was away a lot and I had three children to, I won't say bring up on my own, but it seemed like it at the time and we were trying to sell a house and it was a very stressful period and my husband went away on a trip and came back with a dose 
of 'flu, which I got, and he recovered in three days and I was still poorly three months later'.

Friends had dropped away since she had become ill, and Sharon was pessimistic that her social situation would ever change. Illness was portrayed as a controlling force in her life, causing the loss of many valued roles and activities: I've lost touch with a lot of people, as you do, because I don't have the energy, you know. I've tried all sorts of things like reading circles and things, and you just have to give up, I just had to give up, so that's another thing. So no, I wouldn't say that I've met people or probably ever will, I don't know'.

Sharon had experienced stigma and disbelief in relation to her ME. This social response was also difficult for her to control, and it had profoundly undermined her self-image: 'I did have to battle with various people thinking that it was psychological and I needed to exercise more, etcetera, etcetera...I often think that people must think I'm a hypochondriac'.

Sharon had been a full-time home-maker when her children were young, and, despite her plans, had been unable to take up paid work as they grew older because of her illness. Her ME subsided for a short while after initial onset but then recurred more severely, increasing her search for an explanation to make sense of its unpredictability: 'I think it was a combination of the virus and the stress, which made it happen, I suppose'.

With the exacerbation of her illness, even sedentary activities were beyond her capabilities for a very long time. Her account was studded with repeated references to what she 'couldn't' do. When leisure activities were mentioned, they were belittled with words such as 'just', as in 'just sitting'. Yet ultimately, she discovered a creative medium that allowed her to express her need for meaningful occupation within the 
confines of ill-health. She represented her change of lifestyle as a conscious decision: 'Before I became ill, I always used to like doing knitting and things like that and a lot of reading. When I was first ill, because the mind and brain are so affected, so fatigued, I couldn't even really concentrate on a book for quite a long time and I just sat around mindlessly watching television for a lot of the time. I certainly couldn't do anything like knitting, I couldn't concentrate on a pattern ...Eventually I thought 'I'm fed up with just sitting watching television doing nothing', so I took up tapestry'.

In Sharon's narrative, the discovery of textile art was represented as a turning point in living with ME. Her textile art helped Sharon to re-direct her focus from what she could not do, to what she could do well. She mainly created cross-stitch and tapestry samplers and cushions, presenting geometric patterns and floral designs. The work appeared neat and precise, usually in muted colors. She preferred making cushions as these were 'useful' in the home. Sharon was aware that this form of artmaking might be less personally expressive than other forms. To the interviewer's question about whether she expressed her feelings about her illness in her artwork, she replied: 'No, I don't think so, not in the way that perhaps writing a poem or painting a picture would'.

Yet Sharon had found that art-making enhanced her well-being through allowing her to display creative talents that others appreciated. This experience seemed to have particular meaning, given the limited affirmation offered by her family: 'I know when friends are here and they see one [piece of textile art] that I'm working on, they say, 'Oh goodness, that's so clever, isn't it, so difficult?'.

Although art held certain positive meanings, Sharon's narrative also emphasized her 'stuckness' or stasis on a psychological and physical plateau. She expressed pessimism that either her health or her artistic skills would improve further. She continued to deprecate many of her creative skills and products, using words such 
as ' $j u s t$ ' to express their limited significance: 'I certainly do more difficult things than I used to, but I think I've reached a plateau now, I don't think I find it [artwork] much of a challenge anymore, I think it's just something to do with my hands in the evening, because as I said, I do have to sit down... I have to rest quite a bit still, I do have bad periods, so it's just something to do, I either do that or I read or whatever'.

In keeping with this negative emphasis, Sharon took only limited pleasure in her artwork. For her, it stood as a testament to a path not taken, since it reminded her of all the alternative activities that had been closed to her since the onset of ME: 'I sometimes look around at all these things (textile items) I've got and so many years ill health and it's not something I probably would ever have done if I hadn't been ill, because I'd much rather be more active... I wouldn't say it reminds me of failure, but it does remind me of the fact that I was unable to do anything myself... They remind me of bad times rather than good'.

Sharon experienced a sense of limited agency both in relation to her illness and in relation to her choice of leisure activities. Her narrative was dominated by images of stasis, loss and endings rather than progression or transformation. Sharon made several references to how things had 'ended up', and to being stuck, sedentary, and sitting. 'But needlework is not the thing I would have chosen, in a way, to express my creative side, but, you know, needs must, that's the way it's ended up... I mean the negative side is the fact that I've lived with it and I can't say that I wasted time but all the bad years and years of ill health... and I sometimes get quite stressed and think, oh God, look at me, a sad old person sitting here and sewing away'.

Sharon finished the interview in a rather more upbeat way but this still betrayed her ambivalent attitude towards living with her illness: 'I do believe in finding the good in every situation, but it's a little bit hard sometimes'. 


\section{Case 2: Julia - Artwork represents 'The way forward'.}

Julia had lived with ME for 16 years, but she began the interview by describing her marriage rather than her health condition: 'I'm nearly 62. I'm married to Paul and we celebrate our silver wedding next year'.

As the interview unfolded, Julia emphasized the strength of her marital relationship as pivotal in helping her to cope with ME. Her husband was represented as fully supportive of her artistic endeavors, and as sharing her commitment to raising funds for charity by selling her small hand-made items. 'My husband has been a tower of strength and he understands, and he's never questioned, he's never said... 'you'll feel better soon'. He understands and that has been very supportive'.

Like Sharon, Julia described her ME as having begun with an influenza infection. She experienced the illness as sudden and devastating: 'I was almost bedridden ...I could just get to the bathroom and that lasted for about three months'.

Julia described having a varied career prior to her illness. Initially, she had been a full-time mother. 'You have children and see what happens when the children are grown up and my life took very much that sort of shape'. Once her children were old enough, she had taken various administrative jobs in public services. Julia recollected that her decision to give up work following the onset of ME was reached after a period of emotional and physical struggle in which she endeavored to maintain her roles at work and at home. 'It was extremely difficult, because I felt that I was letting the family down'.

Like the previous participant, Julia's self-image was also challenged not only by her loss of roles within the family but also by other people's misinterpretation of her condition and the stigma of ME. 'When you look reasonably well to people and they say, 'Well, what's the matter with you?' So, in a way you're feeling bad, because you're thinking, I know I feel very ill inside, but you can't describe the 
symptoms to people. I'll tell you what was said to me... 'Put your make-up on, have your hair done and you'll feel a lot better'... I found it quite insulting'.

It took five years for Julia to achieve a measure of acceptance of her condition. As she moved on to describing more recent experiences, her narrative was no longer dominated by the use of the word ' $c a n$ ' $t$ '. Her changed relationship with ME was symbolized in a dream that she recounted: 'I reached a sort of plateau after about five years [with ME] ...This is going to sound strange, up until that time, in my dreams I was a perfectly fit and healthy person who could walk distances, no problem at all. When I got to about five years, in my dreams, I was being chased, [but] my legs had stopped working. So it obviously had affected me very deeply by that time and I was beginning really to feel that after five years, I wasn't going to improve much more, and I haven't, but I've learnt to live with it now'.

Like Sharon, Julia described her physical health as being on a plateau, and she expected little further improvement. Initially, her account could be framed as a chaos or loss narrative dominated by meaninglessness, restriction and unpredictable disorder. After the turning point described above, her account became more positive, and, unlike Sharon, she portrayed herself as moving on from the 'plateau'. Julia described her emotional acceptance of ME as initiating a search for a life-affirming activity that could be performed within the restrictions of her health. She discovered that she could design and make a variety of small textile arts and crafts items for charity, if she selected items that were light enough to handle with minimal fatigue. When describing the meanings of her creative activities and their contribution to her quality of life with ME, Julia referred to her sense of achievement and satisfaction, her enjoyment of color and planning new designs. Her art and craft work also reestablished a sense of continuity with the past, including her childhood interests and family activities. Arguably, such experiences were important for strengthening her 
positive sense of self and for combating the disruption to her life story that had been imposed by CFS/ME: 'My mother did some knitting, but she was brilliant at sewing ... She sewed all our clothes as kids and she did a really super job, a super job. Her sister, my aunt, she was brilliant at knitting and embroidery. Dad used to sketch from time to time and a little bit of painting, so I was always surrounded by craft'.

In talking about the meanings of art-making, Julia used the recurring metaphor of a 'journey'. For example, she referred several times to her developing textile arts and crafts skills as 'another step forward', and alluded to metaphorical movement again when she described her charity work as allowing her to 'pass it on'. Her repeated use of this phrase had various meanings, financial and social, such as passing on money to charity, skills, time, and appreciation of being in a more fortunate position than many other people. Julia was able to sustain a familiar sense of self as a person committed to public service through her charity work. Having spent five years marooned on an emotional and physical 'plateau', she reframed her experience of ME as a journey, facilitated by her art. 'I began to see this glimmer of hope at the end of the tunnel'. She continued with her journey metaphor in describing the meaning of art-making: 'I don't get too down about it [ME], because I have found this other way of moving forward... I've looked back over what had happened to me, my journey of self discovery and I thought I've been lucky in a way that I was able to take that journey. But there are a lot of people who, if they haven't already got the skills, can't take that journey, because they don't know where to go or what to do, or what's available to them'.

Later she continued with the theme of metaphorical movement through the illness experience, using the image of a door opening: 'It (art-making) has made a difference to my life. It was as though someone, the door was ajar and suddenly 
someone flung it open and said 'this is it' ... that's the way forward... I've got something else to turn to, rather than just looking at the things that I can't do'.

\section{Case 3: Grace - Artwork "expresses what I feel at the time"}

Grace began her interview in a somewhat similar way as Sharon, recounting her age, her family context and details of her ME. However, her opening account was more upbeat as it emphasized both her profound physical disability and her gradual psychological improvement: 'I'm 51, I'm divorced and I live with my elderly parents and I've had ME for seventeen years now. Most of the time it's been pretty severe and at the moment I'm virtually bedroom bound, but my brain's quite a bit better'.

Both positive and negative aspects of Grace's situation were therefore evident right from the start of the interview. She described having to give up her professional career in her $30 \mathrm{~s}$ when the illness began. Like the other participants, she attributed its onset to a viral infection, but unlike Sharon, she did not mention stress as a causal factor. Like Sharon, Grace had experienced both remission and then worsening of symptoms. The illness was described as a 'complete mystery'.

Grace's account suggested that she had been even more physically debilitated by ME than the other two participants, yet she interpreted small functional improvements more positively: 'Just this year, I have improved a bit, I go out every three weeks and I do seem to be managing that, providing I go for not too long, a couple of hours at the most and just go somewhere really quiet and not do anything while I'm out, Ijust sit and enjoy the scenery. So yes, that was a big bonus. I also can go downstairs twice a week, which I do in the evenings to have a meal with my parents'.

With her early retirement, divorce and return to her parents' home, Grace had lost most of her adult roles. Her loss of relationships had been more catastrophic than 
the other participants who retained their roles as wives and mothers. Unlike Sharon and Julia, Grace was aware that she used some of her art to express painful feelings about her losses in symbolic ways. All of her watercolor paintings were free- flowing and expressive, rather than striving for 'photographic' accuracy. Unlike the other participants who were displaying their creative items in the home or producing them for sale, Grace had few paintings that she had any intention of displaying to a wider audience. She described two paintings: 'I very much missed not having a husband, you know, a relationship of any kind, so it was that, really, in that particular picture. One of the others is about loneliness, that's the one of the two people walking along the beach. That's what I would really like to be doing, walking along hand in hand with a husband or somebody, just enjoying being with somebody and those two [pictures] really, I suppose, are about loneliness'.

Grace's narrative was dominated by sense of actively struggling to understand the implications of her illness for her sense of self and to limit its effects. She narrated a battle to retain some quality to her life, when illness was 'holding her back': 'I did have a lot of pain at one stage, but I've managed to get that more or less under control, provided I manage what I do and what I eat. I have done fairly well on that. It's just really the energy levels that are holding me back... I have to work very hard at it, really, to keep anything like some quality of life'.

Grace described receiving little emotional support at home, but had, until quite recently, a long and trusting relationship with a psychotherapist which she considered helpful for coping with ME. It is uncertain whether this experience affected her use and understanding of the creative process.

In common with the other participants, Grace took up art-making several years after the onset of ME. Like Sharon, Grace deprecated her initial artistic endeavors, using modifiers such as 'a bit', 'just', 'quite' and so on. Her first efforts were 
described as: 'A bit of watercolor painting, just really to put some colors on paper, you know. I wasn't even trying to do anything like a proper painting or express ideas or feelings, it was just a creative thing of putting colors on the paper and I found that quite satisfying and I felt that I'd achieved something. Even if I just spent a few minutes, you know, a couple of times a week, it was just something tangible. So, Ijust really went on from there'.

Yet as she developed further skills, Grace felt more able to communicate complex emotional meanings. Unlike Sharon who enjoyed achieving very precise abstract and floral patterns in her tapestries, and Julia who focused on creating small aesthetically pleasing products that would be saleable, Grace regarded her artwork as a vehicle for exploring personal feelings about her illness in images that were rich in symbolism. Her ability to find both explicit and symbolic ways to communicate her experiences through art may have been enhanced through her lengthy period of psychotherapy for the depression that followed the onset of ME. Yet in her description, it is also clear that her illness greatly limited her involvement in artistic pursuits. 'I think, it [art] expresses what I feel at the time and I have quite a backlog of things. You know, an idea comes to me and I want to get it onto paper and yes, it takes a long time to do that, because I can still really only do artwork, well, half an hour at the most once a week'.

Grace represented her choice of art medium, watercolor painting, and size of paper, as controlled by her health condition, because she had to find ways of working that were not too demanding physically. It is intriguing to speculate whether she regarded her miniature paintings as accommodating both her delicate physical condition and a fragile psyche. 'A painting is very neatly contained, you know, a box of paint and a pad. At one time I didn't even use a big pad of paper, just a very small pad that my mother got me of A5 size and I did really ... miniature paintings'. 
Grace represented some of her art as symbolizing her feelings and concerns. For example, she showed the interviewer a painting of a map of Britain sprinkled with differently colored images that she said represented significant people and pets. Again, artwork seemed to offer containment of her anxieties. 'That [painting] was really like my own anxiety over all the people that I thought I'd lost, because they were all over the country and I couldn't reach them. You can see all those little yellow suns? All my family, that's where they all are... The little black blobs are my cats, because I'm a cat lover and so it was kind of an anxiety. I was so wanting to feel in a bit more control, that I'd done this map and I'd put all the people on this contained map, and they weren't completely lost to me after all... They're still there somewhere in England, because I'd put a picture to it and it wasn't a kind of nebulous outside prayer somewhere that I can't reach'.

Grace also showed another painting that was rich in symbolism, expressing her feelings of isolation and abandonment. 'I think the one that expressed my feelings when I was at rock bottom is the one [painting] with the black on the left, with the cross ...There's a lot of little figures clinging onto it and I think that was at my lowest point of despair really. There's the world on the right hand side and it's got a little solar system and how I felt was that I was completely outside of the world and even outside of the Solar System in this sort of black nothingness...It took me back, it made me realize how much better I do feel now, you know. More connected even though I am really still very isolated'.

Grace thought that her art-making had allowed her to externalize her feelings and so have a less intensely negative attitude to her illness and the changes that it had brought into her life. 'It somehow took away the intensity of the feeling or lessened the intensity of the feeling, because I suppose it externalized it all... Somehow it seems to make it authentic and valid, you know ... that the feelings that I had were 
valid and they were authentic, because I'd made them real and I'd put them on

paper'. However, she was aware that timing was critical when exploring her most personal feelings: 'I have to wait until I feel it's the time to do it. I suppose yes, when I've come to terms sufficiently, then is the time to do the painting. If I try and do it too soon, it's too painful and it does have the opposite effect'.

Not all of Grace's paintings expressed feelings about illness. These were the paintings that she was willing to display within the home. Some brought her into closer contact with nature, a precious experience now that she was virtually housebound. For example, in accounting for why she had represented a squirrel in one painting and pigs in another, she explained: 'I suppose it's a sort of compensation, the nearest I can get to actually going out there and being with them'.

For Grace, the most physically confined of the three participants, painting had little to do with a need for simple occupation or praise from others. ME had brought her not only physical disability but also huge losses in her adult roles and opportunities for intimacy. Yet she did not communicate a sense of stasis or 'stuckness' like Sharon. Nor did she portray her illness as an onwards journey or quest like Julia, who had focused on her goals of developing artistic skills, making connections with others and being useful, within the limits of her health. Instead, Grace kept returning to the theme of struggle, to wrestling with intense feelings of grief, betrayal and abandonment after the onset of $\mathrm{ME}$, and to her search for emotional validation. Even involvement in the physical act of painting was experienced as a struggle, as the illness withheld energy and concentration. She seemed to have embarked upon an internal quest to find meaning and acceptance. The stories that she told about her paintings seemed to have been influenced by her work in verbal psychotherapy. Grace was not engaged in formal art therapy, yet her art met deep psychological needs. Art was also enabling her to explore new sides to her self: 
'I think I've got very tired of words, I've always been a words person, you know, my university degree was English literature. All the time it was words, thinking about the meaning of words and I was exhausted with words ... I didn't realize when I was starting [painting] just how important an outlet it was going to be to me. But when did I start? ... probably about twelve years now and yes, I don't quite know what I would have done without it'.

Grace appeared to be engaged in a very active struggle, on several fronts, to live positively within the stringent confines of her illness. 'I've realized for a long time now that I need to spend as much of my time as I possibly can doing the most positive things that I can, and maximizing my quality of life and if anything's going to get me better, in the absence of somebody discovering a miracle, that is going to be the way to do it. So, it isn't just the art, it's everything'.

\section{Discussion}

Some common themes emerged in the three participants' narratives of their illness and of art-making in CFS/ME. They emphasized how their illness had severely restricted their activities, relationships and thought processes, themes noted previously in qualitative research into the ME experience (such as the study by Hart \& Grace, 2000). All alluded to the value of art for organizing time, and for experiencing tangible achievement when so many other activities had been lost to ill-health. Yet the narrative analysis revealed that each participant told a distinctive story about her illness and the ways in which art-making helped her to live with her condition.

None of the three participants offered a clear 'chaos' narrative, described by Frank (1995; p97) as expressing an empty, meaningless present, a life 'without sequence or discernable causality'. Unlike Whitehead (2006), who detected chaos narratives in the stories of people with ME, the interviews for this study focused more 
strongly on current life rather than early experiences of ME. It is possible that participants had moved on from a chaos narrative because they had lived with ME for many years, and had used this time for reflection and reconstruction.

Sharon came closest to a chaos narrative, in that she did not envisage further positive change in her health or lifestyle. Yet she also acknowledged some quality to her life and emphasized that art-making provided a number of satisfactions. Sharon's narrative could not be fully aligned with Crossley’s typology either. Whilst she openly expressed loss and sadness at the opportunities that ME had taken away, she did not regard herself as living in an 'empty present'. Rather her story seemed to emphasize stasis more than development or loss. Sharon's narrative presented a very circumscribed world in which she had selected textile art as a feasible activity from a very limited range of options. Her art-making offered her opportunities to express skill, control and precision, all experiences that may have been therapeutic given the uncontrollability of her illness, but she did not think that she used her art to explore or express loss or trauma.

Julia represented both her illness and her art-making, in recent years, as intertwined journeys. Her narrative could be understood as a 'quest', in Frank's typology, or as a conversion/growth story, in Crossley's typology. In common with Frank's description of the quest narrative, Julia's account presented herself as facing suffering 'head-on' for a considerable length of time, gaining positive insights in the process. In her story, art-making had played a key role in enabling her to move from a static 'plateau' to a quest to regain meaning and usefulness in her life. The image of the open door is a powerful one and it has been noted in the artwork of other people living with chronic conditions (such as Fenton, 2000). The image of the journey has also been a recurring image in the artwork of others who have long-term health problems (such as women with cancer, as reported by Borgmann, 2002 and Predeger, 
1996). This study shows, through narrative analysis, that art may signify a journey or open door even when these meanings are not expressed directly in the image that the person creates. For Julia, art-making offered a positive way forwards, not for regaining health but for gaining as much quality to life as her health permitted. It also offered a source of connection, to her personal and family history, her husband (who collaborated in her charity work) and the outside world.

The third participant presented a narrative that possibly fits Frank's typology of a quest, in that it represented a journey into the psyche. Even though painting was a 'leisure' activity, Grace seemed to apply psychotherapeutic understandings to her artmaking. She used many of her watercolor paintings to express and understand the losses that illness had imposed. Her narrative portrayed a 'healing struggle', emphasizing a deep need for mastery, containment and meaning. Unlike some of Crossley's HIV+ participants, who offered conversion/ growth narratives emphasizing the spiritual growth and revised priorities that illness had inspired, Grace did not proclaim that ME offered any welcome new insights, feelings of liberation or challenges to her taken-for granted values. Her goals were more modest, using art to express her feelings of anxiety and grief, and to gain assurance that her feelings of shock, abandonment and so on were valid. Art offered a precious medium for meaning-making now that she had grown 'tired of words'.

Although Grace and Julia both offered 'quest' narratives, this classification risks obscuring substantial differences between their stories, thereby masking their distinctive strategies for finding meaning in their lives and re-establishing a positive sense of self. Julia represented herself as embarked upon a journey into a more fulfilling life, including developing her artistic skills and making a contribution socially through charity fund-raising. Grace's struggle to find validation and meaning in her condition was more convoluted and psychologically exposing. She brought 
more explicit psychotherapeutic understandings to her narrative about illness and artmaking. Her active struggle to make sense of her situation resonates with narratives offered by writers coping with clinical depression (e.g. Solomon, 2001).

\section{Conclusions}

The study identified that participants shared certain common experiences of ME and art-making, but the case study approach also revealed distinctive narratives, each of which implied a rather different understanding of the relationships between art, illness, and self. Only one participant clearly presented art-making as facilitating a journey or quest into a more positive future, although the quest narrative has been described in previous research as common among people living with chronic illness. Another narrative may be understood as conveying an internal journey, with art enabling a 'healing struggle' to take place in which the participant sought understanding and validation of painful feelings. The study also uncovered a 'stasis' narrative which emphasized not only loss but also a measure of satisfaction with daily life, gained through her art-making. The participant positioned herself as resigned to moderate subjective well-being within severe and unchanging physical constraints.

The case study analysis allowed a deeper exploration of individual accounts than can be gained when seeking group-level common themes, and it offered insights about the diverse functions of art-making in living with chronic fatigue. However, this approach does not permit simple generalization. None of the participants were participating in formal art therapy, yet they each took distinctive and meaningful therapeutic experiences from their art that helped them to experience some quality of life within the severe constraints imposed by CFS/ME. For these participants, art offered a positive means of filling empty days, developing a social and artistic self, 
and gaining insight through cathartic self-expression. The accounts reveal how creative art-making can provide a multi-faceted resource for living with CFS/ME.

\section{Implications for art therapy}

Narrative approaches to art therapy recognize that art can offer individuals a means of deconstructing impoverished ways of representing the self, to reclaim an alternative preferred life-story (Carlson, 1997). This study has shown that individuals may turn to art many years after developing a debilitating chronic illness, at a point when they have achieved a certain acceptance that their health is unlikely to improve further. Art-making may then be valued for re-establishing a life that has meaning and quality. Whilst art therapy is often valued for its capacity to elicit deeper symbolic self-expression and catharsis, this study establishes that individuals who live with physical illness can also find therapeutic benefit (such as self-esteem and a sense of personal continuity) in developing their creative skills, and using art in their everyday lives to establish healthy connections with the social and physical world . Leisurebased art seems more likely to embody aesthetic judgements rather than emotional turmoil, but it nevertheless offers many opportunities to recover subjective wellbeing. Art therapists might therefore encourage clients to pursue such activities at the conclusion of therapy, mindful of these potential psychosocial benefits.

For people living with a severe yet stigmatized illness such as CFS/ME, artistic products may be especially valued as a visible testament to a self and a life that is both resisting the impact of illness and yet that also remains circumscribed by illness. The participant who interpreted her art as both a source of satisfaction and yet a witness to time that had been lost to illness might have derived new perspectives from a therapeutic conversation in which she was encouraged her to 'own' her achievements, to question her prevailing negative self-evaluation ('it does remind me 
of the fact that I was unable to do anything myself'), and to explore new creative skills and media for self-expression.

The study suggests that art therapists need to be sensitive to clients' distinct narratives about self, art and illness, if they are to help clients become more aware of the power that unexamined narratives exert on their lifestyle choices and self-image. Much is to be gained from listening for recurring metaphors and motifs (such as the 'journey') in individuals' verbal narratives about their artwork (as noted also by Newell-Walker, 2002). Art therapists who work with individuals who have lived with CFS/ME for many years probably should not assume that art-making can be a curative experience. Rather, as Ferris \& Stein (2002, p.47) suggest, art-making may be better regarded as helping those who live with serious illness to 'unfold the cramped self, uncover losses and strengths, and gain the courage to begin a process of reclamation of story and life'. Further research is required into the meanings of leisure-based and therapeutic art-making for people living with CFS/ME to guide sensitive therapeutic practice.

\section{Acknowledgements}

The authors would like to thank the Arts \& Humanities Research Council (UK) for funding this study and the participants for sharing their stories.

\section{References}

Anderson, J., \& Ferrans, C. (1997). The quality of life of persons with chronic fatigue syndrome. Journal of Nervous and Mental Disease, 185(6), 359-367.

Åsbring, P., \& Närvänen, A. (2002). Women's experiences of stigma in relation to chronic fatigue syndrome and fibromyalgia. Qualitative Health Research, $12(2), 148-160$. 
Borgmann, E. (2002). Art therapy with three women diagnosed with cancer. The Arts in Psychotherapy, 29(5), 245-251.

Bullington, J., Sjöström-Flanagan,C., Nordemar, K., \& Nordemar, R. (2005). From pain through chaos to new meaning: Two case studies. The Arts in Psychotherapy, 32(4), 261-274.

Camic, P. (1999). Expanding treatment possibilities for chronic pain through the expressive arts. In C. Malchiodi (Ed.), Medical art therapy with adults (pp. 43-61). London: Jessica Kingsley Publishers.

Carlson, T. (1997). Using art in narrative therapy: enhancing therapeutic possibilities. The American Journal of Family Therapy, 25 (3), 271-283

Clarke, J., \& James, S. (2003). The radicalized self: The impact on the self of the contested nature of the diagnosis of chronic fatigue syndrome. Social Science \& Medicine, 57(8), 1387-1395.

Crossley, M . (2000). Introducing narrative psychology: Self, trauma and the construction of meaning. Buckingham: Open University Press.

Fenton, J. (2000). Cystic fibrosis and art therapy. The Arts in Psychotherapy, 27(1), $15-25$.

Ferris, B. \& Stein, Y. (2002). Care beyond cancer: The culture of creativity. Illness, Crisis and Loss, 10(1), 42-50.

Frank, A. (1995). The wounded storyteller: Body, illness and ethics. Chicago: University of Chicago Press.

Fukuda, K., Straus, S., Hickie, I., Sharpe, M., Dobbins, J., \& Komaroff, A. (1994). The chronic fatigue syndrome: A comprehensive approach to its definition and study. Annals of Internal Medicine, 121(12), 953-959. 
Hart, B., \& Grace, V. (2000). Fatigue in chronic fatigue syndrome: A discourse analysis of women's experiential narratives. Health Care for Women International, 21(3), 187-201.

Munson, P. (Ed.) (2000). Stricken: Voices from the hidden epidemic of chronic fatigue syndrome. New York: The Haworth Press

Newell-Walker, U. (2002). Getting a picture of the client's world-view: Art-making and subjectivity as evidence. Journal of Social Work Practice, 16(1), 43-54.

Polkinghorne, D.E. (1988). Narrative knowing and the human sciences. Albany, New York: SUNY Press.

Predeger, E. (1996). Womanspirit: A journey into healing through art in breast cancer. Advances in Nursing Science, 18(3) 48-58.

Reynolds, F. (2002). Symbolic aspects of coping with chronic illness through textile arts. The Arts in Psychotherapy, 29(2), 99-106.

Shomon, M. (2004). Living well with chronic fatigue syndrome and fibromyalgia. New York: HarperCollins.

Solomon, A. (2001). The noon-day demon: An atlas of depression. New York: Scribner.

Ware, N. (1998). Sociosomatics and illness course in chronic fatigue syndrome. Psychosomatic Medicine, 60(4), 394-401.

Whitehead, L. (2006). Quest, chaos and restitution: Living with chronic fatigue syndrome/ myalgic encephalomyelitis. Social Science and Medicine, 62(9), 2236-2245.

Yin, R.K. (1994). Case Study Research. London: Sage Publications. 